\title{
Postprandial lipid metabolism in relation to coronary heart disease
}

\author{
BY FREDRIK KARPE
}

\author{
King Gustaf V Research Institute, Department of Medicine, Karolinska Hospital, S-171 76 Stockholm, \\ Sweden
}

The issue of whether chylomicron remnants are atherogenic has been much debated. A number of reports, which will be discussed later, point to a relationship between impaired metabolism of postprandial triacylglycerol-rich lipoproteins and the presence of coronary artery disease (CAD). For the purpose of standardization, the levels of plasma lipids and lipoproteins are generally measured in the fasting state, despite the fact that most of our lives are spent between regular meals. For obvious reasons, no consensus has been reached on how postprandial lipoproteins should be quantified in the clinical setting. A large body of studies from the 1950s and 1960s focused on plasma levels of triacylglycerols after a fatty meal in case-control studies. Unfortunately, the interest declined when it was found that the postprandial triacylglycerol level was closely reflected by fasting plasma concentrations (Nestel, 1964). A few fairly recent studies have used vitamin A supplementation of the test meal leading to retinyl ester (mainly retinyl palmitate; RP) incorporation into chylomicrons and their remnants as a means of tracing intestinal lipoproteins in plasma. It was shown that postprandial plasma concentrations of RP were higher in CAD patients than in healthy subjects (Simpson et al. 1990; Groot et al. 1991). With the discovery of the normal truncated variant of apolipoprotein (apo) B, the apo B-48 which in human subjects is the structural protein of intestinally-derived triacylglycerol-rich lipoproteins, a specific marker for chylomicrons and their remnants was found (Kane et al. 1980). The simultaneous quantification of apo B-48 and apo B-100 in subfractions of triacylglycerol-rich lipoproteins after fat intake has led to a better understanding of the metabolism of postprandial triacylglycerol-rich lipoproteins and of their relationship with CAD. However, there is a complete lack of prospective studies in which postprandial lipid metabolism has been related to future events of CAD or progression of atherosclerosis.

\section{METABOLISM OF CHYLOMICRONS AND THEIR REMNANTS}

Chylomicrons are secreted by the intestine after fat intake. Chylomicron particles contain apo B-48 as the structural protein, which in human subjects is formed exclusively in the intestine after tissue-specific editing of the apo B-100 mRNA (Chan, 1992), the significance of which has not been established. Once the chylomicron particle reaches the plasma compartment, it acquires variants of apo $\mathrm{C}$, in particular apo C-II, to enable efficient unloading of its massive triacylglycerol content after attaching to lipoprotein lipase (EC 3.1.1.34; LPL) bound to the endothelium (Patsch, 1987). In plasma, the chylomicrons and their remnants mix with endogenous lipoproteins. The half-life of chylomicrons is very short; it has been estimated to be approximately $5 \mathrm{~min}$ (Patsch, 1987). The bulk of remnants are taken up by the liver using apo $\mathrm{E}$ as a ligand. The mechanisms behind chylomicron remnant uptake have not been clearly elucidated. Recently, Windler $e t$ al. (1996) suggested the presence of two distinct chylomicron remnant receptors; one indistinguishable from the LDL receptor, which mediates binding and uptake of smaller remnant species; another, as yet unidentified, which removes larger chylomicron remnant species at a high rate. The pivotal role of apo $E$ as a ligand for receptor-mediated uptake of 
remnants is clear from studies in type III hyperlipoproteinaemic patients. The presence of apo $\mathrm{E}_{2}$ allele(s) results in a delayed uptake of chylomicron remnants, and patients with type III hyperlipoproteinaemia who are homozygous for the apo $E_{2}$ allele have a severelyretarded elimination of chylomicron remnants (Hazzard \& Bierman, 1976).

\section{VLDL METABOLISM IN THE POSTPRANDIAL STATE}

VLDL particles are secreted continuously from the liver. In contrast to chylomicrons and their remnants, they are characterized by their apo B-100 content (Chan, 1992). The secretion rate of VLDL is partly determined by the availability of triacylglycerols, whereas the generation of the apo B-100 protein seems to be constant (Chan, 1992). This means that immature triacylglycerol-poor VLDL particles will be degraded intracellularly instead of being secreted. The triacylglycerol substrate for the VLDL secretory pathway derives essentially from three sources, all of which can be regulated by food intake. First, free fatty acids (FFA) generated by lipolysis in adipose tissue through the action of hormonesensitive lipase ( $E C$ 3.1.1.3) provide a major source for the liver triacylglycerol secretion. Second, hepatic uptake of poorly lipolysed remnant particles from either VLDL or chylomicrons can contribute. Furthermore, reduced uptake of FFA in adipose and muscle tissues after LPL-mediated lipolysis of chylomicrons and VLDL redirects FFA to the liver, in particular in the postprandial phase (Coppack et al. 1992; Frayn et al. 1993). Third, the liver has the capacity for de novo synthesis of triacylglycerols, which is most evident in carbohydrate overfeeding. Accordingly, the balance between oxidation of FFA in liver and muscle, and the relative contributions of all these triacylglycerol-FFA flux rates determine the VLDL secretion rate.

After a fatty meal, chylomicrons and VLDL mix in blood and, thus, compete for the same lipolytic pathway (Brunzell et al. 1973). It has been shown that endogenous triacylglycerol-rich lipoproteins accumulate in human plasma after fat intake (Cohn et al. 1988; Karpe et al. 1993b; Schneeman et al. 1993), but the mechanism behind this phenomenon is not obvious, since both an enhanced synthesis and an attenuated lipolysis of VLDL have to be considered. Whether this is due to enhanced liver secretion, decreased removal from plasma, or to competition between large VLDL and chylomicrons for the same lipolytic pathway, or a combination thereof, could not be determined in that study. Björkegren et al. (1996) have recently developed a model in which a short-term intravenous infusion of a triacylglycerol emulsion was administered to human subjects to specifically address the issue of competition for lipolysis between the chylomicron-like emulsion and VLDL. An acute threefold increase in plasma triacylglycerols was accompanied by a consistent linear increase in Svedberg flotation unit $\left(S_{f}\right) 60-400$ apo $\mathrm{B}-100$ during the $60 \mathrm{~min}$ infusion of the chylomicron-like triacylglycerol emulsion. In contrast, the $S_{f} 20-60$ apo B-100 content decreased in most subjects. With the use of stable-isotope tracer techniques and kinetic modelling of the tracer it was shown that reduced catabolism of VLDL was the only reasonable explanation for the accumulation of large VLDL. Clearly, the most likely explanation for the rise in $S_{f} 60-400$ VLDL is delayed lipolysis of the particle due to competition for the sites of LPL action. Furthermore, endogenous triacylglycerol-rich lipoproteins accumulate in rat plasma due to a failure to compete successfully with the chylomicron-like triacylglycerol emulsion for a common lipolytic pathway (Karpe \& Hultin, 1995). Importantly, the increase in the number of triacylglycerol-rich apo B-100-containing lipoprotein particles after fat intake is far greater than that of apo B-48-containing lipoproteins. Schneeman et al. (1993) showed that $80 \%$ of the increase in particle number was accounted for by particles containing apo 
B-100. Similar results were obtained independently by Karpe et al. (1993b) and Cohn et al. (1988). Interestingly, the increase was confined to large VLDL particles, whereas the plasma concentration of small VLDL did not change in response to oral fat intake (Karpe et al. 1993b). Conversely, $80 \%$ of the postprandial increase in triacylglycerols was accounted for by lipoproteins containing apo B-48 (Cohn et al. 1993).

Exchange of lipoprotein core lipids is enhanced and, essentially, a flow of cholesteryl esters from HDL and LDL is balanced by a counterflow of triacylglycerols leaving the expanding pool of triacylglycerol-rich lipoproteins. The increase in cholesterol in the triacylglycerol-rich lipoprotein fraction is, on the other hand, accounted for by VLDL (Schneeman et al. 1993), i.e. up to $90 \%$ of the increase in cholesterol in the triacylglycerolrich lipoprotein fraction after a fatty meal was explained by the elevation in VLDL particle number. Cholesteryl esters are transferred from HDL, and perhaps from LDL, to VLDL in exchange for triacylglycerols. The exchange mechanism is dependent on the concentration of acceptor lipoprotein particles and on the concentration of cholesteryl ester transfer protein (CETP). Several reports testify that the transfer of cholesteryl esters from HDL to the triacylglycerol-rich lipoprotein fraction is enhanced during alimentary lipaemia (Eisenberg, 1985; Dullaart et al. 1989). As a result, HDL is depleted of cholesterol, whereas HDL-particle concentration measured as apo A-I-containing lipoprotein particles with and without apo A-II is unaffected by a fatty meal (Karpe et al. 1993a). Furthermore, Mann et al. (1991) have shown that the exchange of cholesteryl esters is enhanced with increasing plasma triacylglycerol levels in normotriacylglycerolaemic plasma, in contrast to hypertriacylglycerolaemic plasma, in which the excess of acceptor lipoprotein is sufficient to allow CETP to be the rate-limiting factor for the exchange of core lipids. It is likely, therefore, that the massive increase in the number of potential acceptor lipoprotein particles for cholesteryl esters in the postprandial state determines the amount of cholesterol recovered in the VLDL fraction of fasting plasma samples. Zilversmit (1979) hypothesized that postprandial lipaemia is an atherogenic state, and that the cholesterol content of chylomicron remnants is a cornerstone in this hypothesis. Recent studies on postprandial lipoprotein metabolism in which cholesterol has been added to a single fatty meal or to the long-term diet, however, have shown a less-than-expected cholesterol accumulation in the triacylglycerol-rich lipoproteins (Dubois et al. 1994; Ginsberg et al. 1994; Clifton \& Nestel, 1996). The acute effect of adding cholesterol to the diet on lipid composition of postprandial triacylglycerol-rich lipoproteins has recently been investigated by Dubois et al. (1994). The dose-response effect in postprandial lipoprotein fractions of cholesterol enrichment by adding $0,140,280$ or $710 \mathrm{mg}$ cholesterol to a high-fat meal was investigated in ten normolipidaemic subjects. Interestingly, the relative lipid composition (including cholesterol) of the large and small triacylglycerol-rich lipoprotein fractions isolated in the postprandial state was not influenced by the added cholesterol. Total plasma cholesterol increased slightly at the two high-cholesterol doses. There was a small but significant increase in total plasma triacylglycerols which was accounted for by an increase in triacylglycerols in the largest triacylglycerol-rich lipoprotein fraction. Recently, the same investigators have continued this line of research by showing that dietary cholesterol accounts for only a very small proportion of the cholesterol carried as chylomicrons (Dubois et al. 1996). In fact, the calculated proportion of dietary cholesterol present in the chylomicron fraction was only one of ninety-nine cholesterol molecules originating directly from the meal. Accordingly, the contribution of cholesterol-rich chylomicron remnant particles is limited in alimentary lipaemia in comparison with the VLDL remnants. Furthermore, the proportion of cholesterol directly derived from the diet is quantitatively of minor importance in the lipid composition of chylomicron remnants. This 
should be taken into consideration when an evaluation of the relationship between postprandial lipoproteins and development of coronary atherosclerosis is attempted.

\section{REMNANTS OF TRIACYLGLYCEROL-RICH LIPOPROTEINS AND CORONARY ARTERY} DISEASE

Quantification of postprandial triacylglycerol-rich lipoproteins is a major methodological challenge. Many researchers have made use of the chylomicron-specific transport route for vitamin $\mathrm{A}$. After ingestion, vitamin $\mathrm{A}$ is to a large extent incorporated into chylomicron particles as retinyl esters, mainly RP (Goodman, 1980). A major proportion of RP stays within the chylomicron until it is taken up by the liver. There were only minimal signs of exchange of RP between chylomicrons and VLDL in a type I hyperlipidaemic patient (Sprecher et al. 1991). However, a few studies have questioned the applicability of RP as a means of quantifying intestinally-derived triacylglycerol-rich lipoproteins. First, Krasinski et al. (1990) have shown that the postprandial RP pattern in plasma does not always coincide with the postprandial triacylglycerol pattern, and that a substantial proportion of the plasma RP at later time-points after oral fat intake is found in the LDL fraction. Second, we have found that the postprandial elevations in apo B-48 and RP in fractions of triacylglycerol-rich lipoproteins do not coincide, and that there are many more RP molecules per apo B-48 molecule in the largest $\left(S_{\mathrm{f}}>400\right.$ fraction) particles compared with the smaller ones $\left(S_{\mathrm{f}} 60-400\right.$ and $S_{\mathrm{f}} 20-60$ fractions; Karpe et al. 1995). Third, separation of apo B-100-containing lipoproteins from apo B-48-containing lipoproteins by immunoaffinity chromatography indicates that RP is found in VLDL (apo B-100-containing lipoproteins), in particular at later time-points after oral fat intake (Cohn et al. 1993). It should be emphasized, therefore, that RP is a marker of chylomicrons and their remnants only with limited specificity. These recent findings suggest that the interpretation of clinical studies using RP measurements after a fat load is confounded by the transfer of RP to apo B-100-containing lipoproteins, in particular at later time-points after an oral fat load.

The clearance of RP was delayed in subjects with documented presence of CAD (coronary angiogram) compared with disease-free subjects (Weintraub et al. 1996). The groups were matched for fasting plasma triacylglycerols. A second (and nowadays neglected) way of quantifying postprandial triacylglycerol-rich lipoproteins is the mere determination of plasma triacylglycerols. Peak plasma triacylglycerols after fat intake have been shown to reflect mainly the fasting plasma level, but the triacylglycerol concentration measured at later time points after an oral fat load seems to be a potential discriminator for the presence of CAD (Patsch et al. 1992). Interestingly, Uiterwaal et al. (1994) showed an exaggerated triacylglycerolaemic (only at later time-points after fat intake) response to a fatty meal in sons of patients with angiogram-documented presence of CAD compared with sons of healthy men. Furthermore, there was no difference in fasting plasma triacylglycerols. This study argues for an important heritable trait determining the triacylglycerolaemic outcome of a fat challenge. It could be argued, therefore, that plasma triacylglycerols measured at later time-points after fat intake might reflect a type of fat intolerance that is of clinical importance.

In human subjects, specific quantification of chylomicrons and chylomicron remnants can only be achieved by direct determination of the plasma concentrations of apo B-48. A method for specific quantification of apo B-48 and apo B-100 has been described by Poapst et al. (1987). Recently, Zilversmit \& Shea (1989) also evaluated the quantification of apo B-48 and apo B-100 using SDS-PAGE, gel scanning and radio-iodination. A similar approach has been adopted by us (Karpe \& Hamsten, 1994) and more recently by others 
(Kotite et al. 1995). Furthermore, we have shown that overloading of apo B-100 on the analytical SDS-PAGE gel is the principal cause for discrepant results regarding the chromogenicity of the apo B variants previously reported in the literature (Poapst et al. 1987).

As previously discussed in detail, it has become apparent that the apo B-100containing triacylglycerol-rich lipoproteins constitute an overwhelming majority of the apo B-containing lipoproteins present in the postprandial state (Karpe et al. 1993b, 1995; Schneeman et al. 1993; Karpe \& Hamsten, 1994; Havel, 1994). Chylomicrons and chylomicron remnants account for $10 \%$ or at most $20 \%$ of the total increase in triacylglycerol-rich lipoprotein particles after fat intake. In addition, it has become apparent that the postprandial state modulates both the metabolism and composition of the apo B-100-containing lipoprotein particles (Karpe et al. 1993b). It is justified, therefore, to include VLDL remnants in the discussion of the importance of remnant lipoproteins in CAD progression. Two studies suggest a relationship between elevated postprandial levels of chylomicron remnants and the presence of CAD. First, Simons et al. (1987) showed that the relative enrichment of apo B-48 compared with apo B-100 in the $S_{f}>60$ lipoprotein fraction sampled $4 \mathrm{~h}$ after fat intake was significantly greater among CAD patients compared with controls. Unfortunately, the results of this study are difficult to interpret since there was also a significant difference in baseline plasma triacylglycerols. The difference found in the $4 \mathrm{~h}$ sample, which would coincide with the peak plasma triacylglycerol level, is just as likely, therefore, to reflect the baseline difference between the groups. Second, we have shown that the postprandial concentrations of small chylomicron remnants (apo B-48 in the $S_{\mathrm{f}}$ 20-60 lipoprotein fraction) after a mixed-meal type of oral fat tolerance test correlates with the 5 -year progression of coronary atherosclerosis, as determined by repeated coronary angiographies, in young postinfarction patients (Karpe et al. 1994). The patients in this study were, however, highly selected. First, females and patients with severe hyperlipoproteinaemia were not investigated. Second, a certain number of patients died in the course of the follow-up period. It is also evident from this study that apo B-48-containing lipoproteins only constitute a very small proportion of the total population of triacylglycerol-rich lipoproteins in plasma. Thus, the interpretation of these data is not entirely straightforward, not least as the concentrations of apo B-48 correlated significantly with the plasma levels of small, dense LDL (Karpe et al. 1993c). It can be argued, therefore, that impaired handling of postprandial triacylglycerols is another aspect of the 'atherogenic lipoprotein phenotype'. A similar conclusion was indicated by results reported for a group of noninsulin-dependent diabetic patients (Tan et al. 1995). As the metabolism of endogenous and exogenous triacylglycerol-rich lipoproteins are so tightly linked it is reasonable also to discuss studies relating VLDL variables to the presence of CAD. Two recent studies suggest that 'VLDL remnants' are linked to progression of CAD (Phillips et al. 1993; Tornvall et al. 1993). Furthermore, the MARS study, which is an angiographic, randomized, double-blind, placebo-controlled 2-year trial of Lovastatin monotherapy, indicates that triacylglycerol-rich lipoproteins are specifically linked to progression of mild to moderate coronary lesions (Hodis et al. 1994).

An important contribution relating to this issue has been reported by Rapp et al. (1994), who isolated triacylglycerol-rich lipoproteins by selected-affinity anti-apo B immunosorbtion from human atherosclerotic plaques. The methodology included thorough precautions to avoid degradation of the lipoproteins before and during the isolation procedure. Intact triacylglycerol-rich lipoproteins were isolated from the plaque tissue. These lipoproteins resembled the triacylglycerol-rich lipoproteins circulating in plasma, 
except for a slightly larger particle size. Thus, this study clearly demonstrated that triacylglycerol-rich lipoproteins are deposited in the atherosclerotic plaque.

Taken together, future clinical studies of the relationship between postprandial lipoproteins and CAD should include more than the measurement of chylomicron remnants. In terms of generation of potentially-atherogenic remnant lipoproteins after fat intake, the apo B-100 containing lipoproteins seem to be of major importance. Furthermore, hypertriacylglycerolaemia, in particular prolonged alimentary lipaemia, has been hypothesized to be a hypercoagulable condition (Hamsten, 1993).

This study was supported by grants from the Swedish Medical Research Council (8691), the Swedish Heart-Lung Foundation, the Fredrik and Ingrid Thuring Foundation, the Professor Nanna Svartz' Fund, and the Swedish Margarine Industry Fund for Research on Nutrition.

\section{REFERENCES}

Björkegren, J., Packard, C. J., Hamsten, A., Bedford, D., Caslake, M., Foster, L., Shepherd, J., Stewart, P. \& Karpe, F. (1996). Accumulation of large very low density lipoprotein in plasma during intravenous infusion of a chylomicron-like triglyceride emulsion reflects competition for a common lipolytic pathway. Journal of Lipid Research 37, 76-86.

Brunzell, J. D., Hazzard, W. R., Porte, D. \& Bierman, E. L. (1973). Evidence for a common, saturable, triglyceride removal mechanism for chylomicrons and very low density lipoproteins in man. Journal of Cinical Investigation 52, 1578-1585.

Chan, L. (1992). Apoliprotein B, the major protein component of triglyceride-rich and low density lipoprotein. Journal of Biological Chemistry 267, 25621-25624.

Clifton, P. M. \& Nestel, P. J. (1996). Effect of dietary cholesterol on postprandial lipoproteins in three phenotypic groups. American Journal of Clinical Nutrition 64, 361-367.

Cohn, J. S., Johnson, E. J., Millar, J. S., Cohn, S. D., Milne, R. W., Marcel, Y. L., Russel, R. M. \& Schaefer, E. J. (1993). Contribution of apoB-48 and apoB-100 triglyceride-rich lipoproteins (TRL) to postprandial increases in the plasma concentration of TRL triglycerides and retinyl esters. Jourmal of Lipid Research 34, $2033-2040$.

Cohn, J. S., McNamara, J. R., Cohn, S. D., Ordovas, J. M. \& Schaefer, E. J. (1988). Plasma apolipoprotein changes in the triglyceride-rich lipoprotein fraction of human subjects fed a fat-rich meal. Journal of Lipid Research 29, 925-936.

Coppack, S. W., Evans, R. D., Fisher, R. M., Frayn, K. N., Gibbons, G. F., Humphreys, S. M., Kirk, M. L., Potts, J. \& Hockaday, T. D. (1992). Adipose tissue metabolism in obesity: lipase action in vivo before and after a mixed meal. Metabolism 41, 264-272.

Dubois, C., Armand, M., Ferezou, J., Beaumier, G., Portugal, H., Pauli, A.-M., Bernard, P.-M., Becue, T., Lafont, H. \& Lairon, D. (1996). Postprandial appearance of dietary deuterated cholesterol in the chylomicron fraction and whole plasma in healthy subjects. American Journal of Clinical Nutrition 64, 47-52.

Dubois, C., Armand, M., Mekki, N., Portugal, H., Pauli, A.-M., Bertrand, P.-M., Lafont, H. \& Lairon, D. (1994). Effects of increasing amounts of dietary cholesterol on postprandial lipemia and lipoproteins in human subjects. American Journal of Clinical Nutrition 35, 1993-2007.

Dullaart, R. P. F., Groener, J. E. M., van Wijk, H., Sluiter, W. J. \& Erkelens, D. W. (1989). Alimentary lipemiainduced redistribution of cholesterol ester between lipoproteins. Studies in normolipidemic, combined hyperlipidemic, and hypercholesterolemic men. Arteriosclerosis 9, 614-622.

Eisenberg, S. (1985). Preferential enrichment of larger-sized very low density lipoprotein populations with transferred cholesteryl esters. Journal of Lipid Research 26, 487-494.

Frayn, K. N., Coppack, S. W., Humphreys, S. M., Clark, M. L. \& Evans, R. D. (1993). Periprandial regulation of lipid metabolism in insulin-treated diabetes mellitus. Metabolism 42, 504-510.

Ginsberg, H. N., Karmally, W., Siddiqui, M., Holleran, S., Tall, A. R., Rumsey, S. C., Deckelbaum, R. J., Blaner, W. S. \& Ramakrishnan, R. (1994). A dose-response study of the effects of dietary cholesterol on fasting and postprandial lipid and lipoprotein metabolism in healthy young men. Arteriosclerosis \& Thrombosis 14, 576-586.

Goodman, D. S. (1980). Vitamin A metabolism. Federation Proceedings 39, 2716-2722.

Groot, P. H. E., van Stiphout, W. A. H. J., Krauss, X. H., Jansen, H., van Tol, A., van Ramshorst, E., Chin-On, S., Hofman, A., Cresswell, S. R. \& Havekes, L. (1991). Postprandial lipoprotein metabolism in normolipidemic men with and without coronary heart disease. Arteriosclerosis \& Thrombosis 11, 653-662.

Hamsten, A. (1993). The hemostatic system and coronary heart disease. Thrombosis Research 70, 1-38. 
Havel, R. J. (1994). Postprandial hyperlipidemia and remnant lipoproteins. Current Opinion in Lipidology 5, $102-109$.

Hazzard, W. R. \& Bierman, E. L. (1976). Delayed clearance of chylomicron remnants following vitamin-Acontaining oral fat loads in broad- $\beta$ disease (Type III hyperlipoproteinemia). Metabolism 25, 777-801.

Hodis, H. N., Mack, W. J., Azen, S. P., Alaupovic, P., Pogoda, J. M., LaBree, L., Hemphill, L. C., Kramsch, D. M. \& Blankenhorn, D. H. (1994). Triglyceride- and cholesterol-rich lipoproteins have differential effect on mild/moderate and severe lesion progression as assessed by quantitative coronary angiography in a controlled trial on Lovastatin. Circulation 90, 42-49.

Kane, J. P., Hardman, D. A. \& Paulus, H. E. (1980). Heterogeneity of apolipoprotein B: Isolation of a new species from human chylomicrons. Proceedings of the National Academy of Sciences USA 77, 2465-2469.

Karpe, F., Bard, J.-M., Steiner, G., Carlson, L. A., Fruchart, J.-C. \& Hamsten, A. (1993a). HDLs and alimentary lipemia. Studies in men with previous myocardial infarction at young age. Arteriosclerosis \& Thrombosis 13, $11-22$.

Karpe, F., Bell, M., Björkegren, J. \& Hamsten, A. (1995). Quantification of postprandial triglyceride-rich lipoproteins in healthy men by retinyl ester labeling and simultaneous measurement of apolipoproteins B-48 and B-100. Arteriosclerosis, Thrombosis and Vascular Biology 15, 199-207.

Karpe, F. \& Hamsten, A. (1994). Determination of apolipoproteins B-48 and B-100 in triglyceride-rich lipoproteins by analytical SDS-PAGE. Journal of Lipid Research 35, 1311-1317.

Karpe, F. \& Hultin, M. (1995). Endogenous triglyceride-rich lipoproteins accumulate in rat plasma when competing with a chylomicron-like triglyceride emulsion for a common lipolytic pathway. Journal of Lipid Research 36, 1557-1566.

Karpe, F., Steiner, G., Olivecrona, T., Carlson, L. A. \& Hamsten, A. (1993b). Metabolism of triglyceride-rich lipoproteins during alimentary lipemia. Journal of Clinical Investigation 91, 748-758.

Karpe, F., Steiner, G., Uffelman, K., Olivecrona, T. \& Hamsten, A. (1994). Postprandial lipoproteins and progression of coronary atherosclerosis. Atherosclerosis 106, 83-97.

Karpe, F., Tornvall, P., Olivecrona, T., Steiner, G., Carlson, L. A. \& Hamsten, A. (1993c). Composition of human low density lipoprotein: effects of postprandial triglyceride-rich lipoproteins, lipoprotein lipase, hepatic lipase and cholesteryl ester transfer protein. Atherosclerosis 98, 33-49.

Kotite, L., Bergeron, N. \& Havel, R. J. (1995). Quantification of apolipoproteins B-100, B-48, and E in human triglyceride-rich lipoproteins. Journal of Lipid Research 36, 890-900.

Krasinski, S. D., Cohn, J. S., Russell, R. M. \& Schaefer, E. J. (1990). Postprandial plasma vitamin A metabolism in humans: a reassessment of the use of plasma retinyl esters as markers for intestinally derived chylomicrons and their remnants. Metabolism 39, 357-365.

Mann, C. J., Yen, F. T., Grant, A. M. \& Bihain, B. E. (1991). Mechanism of plasma cholesteryl ester transfer in hypertriglyceridemia. Journal of Clinical Investigation 88, 2059-2066.

Nestel, P. J. (1964). Relationship between plasma triglycerides and removal of chylomicrons. Journal of Clinical Investigation 43, 943-949.

Patsch, J. (1987). Postprandial lipaemia. Baillère's Clinical Endocrinology and Metabolism 1, 557-580.

Patsch, J. R., Miesenböck, G., Hopferwieser, T., Muhlberger, V., Knapp, E., Dunn, J. K., Gotto, A. M. \& Patsch, W. (1992). Relation of triglyceride metabolism and coronary artery disease. Studies in the postprandial state. Arteriosclerosis \& Thrombosis 12, 1336-1345.

Phillips, N. R., Waters, D. \& Havel, R. J. (1993). Plasma lipoproteins and progression of coronary artery disease evaluated by angiography and clinical events. Circulation 88, 2762-2770.

Poapst, M., Uffelman, K. \& Steiner, G. (1987). The chromogenicity and quantitation of apoB-100 and apoB-48 of human plasma lipoproteins on analytical SDS gel electrophoresis. Atherosclerosis 65, 75-88.

Rapp, J. H., Lespine, A., Hamilton, R. L., Colyvas, N., Chaumeton, A. H., Tweedie-Hardman, J., Kotite, L., Kunitake, S. T., Havel, R. J. \& Kane, J P. (1994). Triglyceride-rich lipoproteins isolated by selected-affinity anti-apolipoprotein B immunosorbtion from human atherosclerotic plaque. Arteriosclerosis \& Thrombosis 14, $1767-1774$.

Schneeman, B. O., Kotite, L., Todd, K. M. \& Havel, R. J. (1993). Relationship between the responses of triglyceride-rich lipoproteins in blood plasma containing apolipoproteins B-48 and B-100 to a fat-containing meal in normolipidemic humans. Proceedings of the National Academy of Sciences USA 90, 2069-2073.

Simons, L. A., Dwyer, T., Simons, J., Bernstein, P., Mock, P., Poonia, N. S., Balasubramaniam, S., Baron, D., Branson, J., Morgan, J. \& Roy, P. (1987). Chylomicrons and chylomicron remnants in coronary artery disease: a case-control study. Atherosclerosis 65, 181-189.

Simpson, H. S., Willamson, C. M., Olivecrona, T., Pringle, S., Maclean, J., Lorimer, A. R., Bonnefous, F., Bogaievsky, Y., Packard, C. J. \& Shepherd, J. (1990). Postprandial lipaemia, fenofibrate and coronary heart disease. Atherosclerosis 85, 653-662.

Sprecher, D. L., Knauer, S. L., Black, D. M., Kaplan, L. A., Akeson, A. A., Dusing, M., Lattier, D., Stein, E. A., Rymaszewski, M. \& Wiginton, D. A. (1991). Chylomicron-retinyl palmitate clearance in type I hyperlipidemic families. Journal of Clinical Investigation 88, 985-994.

Tan, K. C., Cooper, M. B., Ling, K. L., Griffin, B. A., Freeman, D. J., Packard, C. J., Shepherd, J., Hales, C. N. \& Betteridge, D. J. (1995). Fasting and postprandial determinants for the occurrence of small dense LDL species 
in non-insulin-dependent diabetic patients with and without hypertriglyceridaemia: the involvement of insulin, insulin precursor species and insulin resistance. Atherosclerosis 113, 273-287.

Tornvall, P., Båvenholm, P., Landou, C., de Faire, U. \& Hamsten, A. (1993). Relation of plasma levels and composition of apolipoprotein B-containing lipoproteins to angiographically defined coronary artery disease in young patients with myocardial infarction. Circulation 88, 2180-2189.

Uiterwaal, C. S. P. M., Grobbee, D. E., Witteman, J. C. M., van Stiphout, W.-A. H. J., Krauss, X. H., Havekes, L. M., de Bruijn, A. M., van Tol, A. \& Hofman, A. (1994). Postprandial triglyceride responses in young adult men and familial atherosclerosis. Annals of Internal Medicine 121, 576-583.

Weintraub, M. S., Grosskopf, I., Rassin, T., Miller, H., Charach, G., Rotmensch, H. H., Liron, M., Rubinstein, A. \& Iaina, A. (1996). Clearance of chylomicron remnants in normolipidemic patients with coronary artery disease: case control study over three years. British Medical Journal 312, 935-939.

Windler, E., Greeve, J., Robenek, H., Rinniger, H., Greten, H. \& Jäckle, S. (1996). Differences in the mechanisms of uptake and endocytosis of small and large chylomicron remnants by rat liver. Hepatology 24, 344-351.

Zilversmit, D. B. (1979). Atherogenesis: a postprandial phenomenon. Circulation 60, 473-485.

Zilversmit, D. B. \& Shea, T. M. (1989). Quantification of apoB-48 and apoB-100 by gel scanning and radioiodination. Journal of Lipid Research 30, 1639-1646. 